\title{
Swimming against the tide in STEM education and gender equality: a problem of recruitment or retention in Malaysia
}

Siew Ching Goy ${ }^{a}$, Yut Lin Wong ${ }^{b}$, Wah Yun Low ${ }^{c}$, Siti Nurani Mohd Noor ${ }^{d}$, Zahra FazliKhalaf $^{e}$, Nkechi Onyenehof, Esther Daniel ${ }^{g}$, SuzanaAriff Azizan ${ }^{d}$, Maisarah Hasbullah ${ }^{d}$ and Anthonia GinikaUzoigwe ${ }^{\text {h }}$

${ }^{\mathrm{a}}$ Faculty of Social Sciences, Universiti Malaysia, Sarawak, Malaysia; ${ }^{\mathrm{b}}$ Department of Social and Preventive Medicine, University of Malaya, Kuala Lumpur, Malaysia; ${ }^{C}$ Faculty of Medicine, University of Malaya, Kuala Lumpur, Malaysia; ${ }^{\mathrm{d} D e p a r t m e n t}$ of Science and Technology, Faculty of Science, University of Malaya, Kuala Lumpur, Malaysia; ${ }^{\text {DDivision }}$ of Psychology, International Medical University, Kuala Lumpur, Malaysia; fDepartment of Sociology and

Anthropology, University of Nigeria, Nsukka, Nigeria; ${ }^{9}$ Department of Mathematics and Science Education, Faculty of

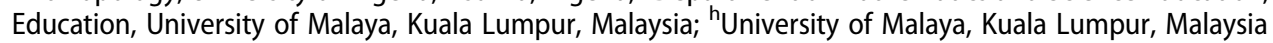

\begin{abstract}
Science, technology, engineering and mathematics (STEM) is acknowledged as one of the key drivers of technological innovation. Malaysian women join the educational pipeline as equals to their male counterparts. Nevertheless, women are persistently under-represented in technology and engineering, but over-represented in other STEM fields. Using data provided by the Malaysian Ministry of Higher Education, our results suggest that under-representation of women in engineering was attributed to low recruitment at the point of entry. Such a finding thus begs the question as to why women were not recruited into engineering. Malaysian policymakers and educators need to address under-representation of women in order to achieve gender equality in STEM, as part of the goals of Millennium Development and Vision 2020; to become a nation that is competent, confident and innovative in harnessing and advancing science and technology.
\end{abstract}

\section{KEYWORDS}

STEM; gender gap;

education; representation; retention

\section{Background}

Gender disparity in science, technology, engineering and mathematics (STEM) education is a known fact in higher learning institutions. Cronin and Roger (1999) note that women's absence in STEM exhibits a progressive pattern all the way up the pipeline. The loss starts as early as the secondary school level among girls who have choice (Stewart 1998). When young students apply for placement in universities, some qualified science students irrespective of gender switch to non-STEM disciplines as their major. Among those enrolled into STEM fields, some may change their major before graduation. The general belief is that women persist at a rate lower than their male counterparts in STEM in general and engineering in particular (Chubin, May, and Babco 2005). This notion however is not well supported. Seymour and Hewitt (1997) and Lord et al. (2009) showed that women are as likely as men to persist in engineering. In contrast, Astin and Astin (1992) and Adelman (1998) found a notable gender gap in STEM persistence, in favour of men. That said, when ability of students is controlled for in the analysis, Adelman (1998) found no significant gender gap in engineering persistence rate. What is the relationship between representation and retention across genders in STEM in a rapidly developing country such as Malaysia? 